\title{
(2) OPEN ACCESS \\ I spy with my little eye ... a knee about to go 'pop'? Can coaches and sports medicine professionals predict who is at greater risk of $A C L$ rupture?
}

\author{
Anne Inger Mørtvedt $\odot,{ }^{1}$ Tron Krosshaug, ${ }^{2}$ Roald Bahr, ${ }^{2}$ Erich Petushek ${ }^{3,4}$
}

\begin{abstract}
'Department of Sports Medicine, Norwergian School of Sport Sciences, Oslo Sports Trauma Research Center, Oslo, Norway ${ }^{2}$ Department of Sports Medicine, Norwegian School of Sport Sciences, Oslo Sports Trauma Research Center, Oslo, Norway ${ }^{3}$ College of Human Medicine, Michigan State University, East Lansing, Michigan, USA

${ }^{4}$ Department of Cognitive and Learning Sciences, Michigan

Technological University, Houghton, Michigan, USA
\end{abstract}

\section{Correspondence to}

Dr Tron Krosshaug, Department of Sports Medicine, Norwegian School of Sport Sciences, Oslo Sports Trauma Research Center, 0863 Oslo, Norway; tron.krosshaug@nih.no

Accepted 18 September 2019 Published Online First 14 October 2019

\section{ABSTRACT}

Background The vertical drop jump (VDJ) test is widely used for clinical assessment of ACL injury risk, but it is not clear whether such assessments are valid.

Aim To examine if sports medicine professionals and coaches are able to identify players at risk of sustaining an ACL injury by visually assessing player performance during a VDJ test.

Methods 102 video clips of elite female handball and football players performing a baseline VDJ test were randomly extracted from a 738-person prospective cohort study that tracked $A C L$ injuries. Of the sample, 20 of 102 went on to suffer an ACL injury. These 102 videos were uploaded to an online survey. Sports medicine professionals and coaches were invited to assess athlete performance and rate each clip with a number between 1 and 10 (1 representing low risk of sustaining an $\mathrm{ACL}$ injury and 10 representing high risk). Receiver operating characteristic analyses were used to assess classification accuracy and between-group differences were analysed using one-way analysis of variance.

Results 237 assessors completed the survey. Area under the curve values ranged from 0.36 to 0.60 , with a mean score of 0.47 , which is similar to random guessing. There were no significant differences in classification accuracy between groups (physicians, coaches, certified athletic trainers, researchers or physical therapists).

Conclusion Assessors have poor predictive ability (no better than chance), indicating that visual assessment of a VDJ test is a poor test for assessing ACL injury risk in elite female handball and football players.

\section{INTRODUCTION}

Observational assessment of movement quality is believed to represent a critical component in effective ACL injury prevention programme, ${ }^{12}$ and the vertical drop jump (VDJ) test is widely used clinically to assess ACL injury risk. Since simple observation requires no tools, is fast and inexpensive, it can be useful for large-scale application. However, it is not clear whether such assessments are valid. Previous studies have shown that the assessment of movement patterns by experienced personnel during a drop jump corresponds well with that of sophisticated three-dimensional-analyses. ${ }^{3-9}$ Nonetheless, no studies have investigated whether simple observation can be used to prospectively identify elite athletes at increased risk for ACL injury.

Previous analyses of injury situations ${ }^{10-13}$ show that distinct movement patterns are associated with ACL injury, such as greater internal hip rotation and knee valgus. It is assumed that similar movement patterns, hypothesised to predispose the athlete for increased risk of injury, may be revealed in jump landings, ${ }^{14}$ in particular frontal plane knee motion. ${ }^{361516}$ Therefore, the VDJ has been used extensively as a screening test for assessing ACL injury risk in the clinic and in scientific studies. ${ }^{17-19}$

In an early study using three-dimensional motion analysis techniques, Hewett et $a l^{17}$ reported that increased knee abduction moment and ground reaction force (GRF) were associated with increased injury risk in young, female adolescent athletes. Later, Leppänen et $a l^{19}$ reported that GRF, but not frontal plane variables, was associated with injury in a similarly aged cohort, while Krosshaug et $a l^{18}$ found that neither GRF nor knee abduction moment was associated with ACL injury in their cohort of elite female athletes. However, although three-dimensional motion analysis is considered a gold standard, it is well known that substantial errors may occur. These errors may originate from, for example, identification of bony landmarks and skin artefacts. Thus, simple visual assessment could provide different results. In three-dimensional analysis, the data are typically reduced from continuous movement patterns to peak values, that may or may not be critical for the injury event, and thus vital information may be lost. Moreover, from machine learning, we know that even advanced algorithms, based on extensive sensory input, such as for example, three-dimensional analysis systems, may not evaluate situations as well as humans. ${ }^{20}$ It is therefore possible that the human eye and brain can detect and assess critical movement characteristics associated with increased risk for injury better than those based on discrete data points.

The purpose of this study was to examine whether sports medicine professionals and coaches could visually identify female elite football and handball players with increased risk for ACL injury based on their performance on a VDJ test, and to investigate which cues that are used in the assessment. Furthermore, we examined whether professional groups within sport and sports medicine (eg, physiotherapists, coaches) differed in their ability to assess ACL injury.

\section{METHODS}

\section{Study design}

Sports medicine professionals (including students) and coaches all over the world were invited through email and social media platforms to rate the risk of a sample of Norwegian female handball and football premier league players. Video clips of 
102 players, including 20 players who sustained an ACL injury during the study period (subsequent to the video recording) were made available online, allowing anyone with access to the link to participate anonymously. The face of the athletes was blurred to protect their anonymity. The current study did not involve patients.

The videos and injury information had been collected previously, through the Oslo Sports Trauma Research Center ACL risk factor study, where all teams in the Norwegian female handball and football premier league were invited to a preseason baseline screening including videotaping of three valid VDJs. ${ }^{182122}$ The VDJ tests were recorded from a frontal plane view only.

\section{DATA MATERIAL}

We used video material from 2009 to 2013 as the video quality was uniform (the picture quality was poorer in the previous years). Seven hundred and thirty-eight female players were tested between 2009 and 2013 (474 football players, 264 handball players). Seventy-three of these players were excluded due to previous ACL injury. Among the remaining 665 players, we recorded 31 new injuries during the study period. From these, we excluded one direct contact injury. This left us with 633 uninjured and 30 injured players available for randomisation.

We decided in advance to limit the number of video clips to approximately 100, to prevent drop-out by assessors. The ACL injury prevalence in this cohort is approximately $10 \%,{ }^{23}$ hence, 10 injury cases and 90 non-injury cases would represent the natural ratio between injured and non-injured. However, we decided to include a random sample of 20 injury cases in order to ensure sufficient power for the signal detection analysis. Thus, the number of uninjured players was reduced from 90 to 82 , resulting in a total sample of 102 players. To ensure validity, a sensitivity analysis was conducted to explore how manipulating the injury ratio influenced statistical outcomes.

The 20 players ( $n=16$ football, $n=4$ handball) who sustained an ACL injury during the follow-up period were $20 \pm 3$ years, weighed $66 \pm 16 \mathrm{~kg}$ and measured $170 \pm 38 \mathrm{~cm}$. The 82 uninjured players (age $21 \pm 4$ years, weight $63 \pm 14 \mathrm{~kg}$, height $169 \pm 37 \mathrm{~cm}$; 51 football; 31 handball) were randomly selected from the sample of non-injured players.

Players signed a written consent form before inclusion and the Regional Committee for Medical Research Ethics, the South Eastern Norway Regional Health Authority and the Norwegian Social Science Data Services approved the study. All complete ACL injuries among the tested players were recorded throughout March 2014. Moreover, all injuries were verified by MRI and/ or arthroscopy.

\section{Recruitment of assessors}

Recruitment of assessors took place in the period between 22 March and 27 April 2017. Invitations were sent through email with a direct link to the online survey. Email addresses were collected through email lists from different academies, conferences, universities, workplaces, courses and so on. The survey link was also distributed on the social media platforms Facebook and Twitter. Colleagues worldwide helped recruit assessors. We aimed to invite various groups within sport and sports medicine, including coaches, strength and conditioning coaches, athletic trainers, physicians, physiotherapists and researchers both nationally and internationally. Participants identified their profession in the questionnaire. No incentives for participation were given.

\section{ONLINE SURVEY}

The videos were embedded within Qualtrics (2017 Qualtrics LCC) in March 2017. Instructions on how to conduct the survey, followed by one test clip, were given initially. The assessors subsequently watched each clip following a 3-2-1 countdown. One clip lasted for two to three seconds (excluding the countdown), and the assessors could watch each clip as many times as needed. Assessors were asked to rate the clip with a number between 1 and 10, where 1 represented very low risk and 10 represented very high risk (figure 1 ). The assessors were not given any specific cues in advance. After completing all video assessments, they were asked to report what they based their assessment on, in a free text field before rating the importance of different predefined cues with a number between 1 and 10 . Moreover, they were asked to rate their confidence level for the risk rating assessment with a number between 1 and 10. Finally, we recorded gender, age, region, current occupation, education level, work experience level, if they were working with athletes and within which sport and whether or not they had assessed the VDJ test before.

\section{STATISTICAL ANALYSIS}

Receiver operating characteristic (ROC) curves and subsequent areas under the curve (AUC) with 95\% CIs were calculated to describe the diagnostic ability of each assessor to identify players with increased ACL injury risk. We report the AUC as the mean with 95\% CI for each of the occupational groups. For missing data in the risk rating assessment, the mean value for the clip was inserted. The level of accuracy was classified as outstanding (AUC 0.9-1), excellent (AUC 0.8-0.9), acceptable (AUC 0.7-0.8), poor (AUC 0.6-0.7) or no discrimination (AUC $0.5-0.6) .{ }^{24}$ Differences between groups were analysed using oneway analysis of variance with Bonferroni post hoc corrections.

In addition to ROC analyses, we used independent sample t-tests to compare aggregate ratings for the injured/non-injured athletes. This 'wisdom of crowds' type of analysis combined the ratings of multiple assessors to determine whether the collective may be more accurate than individual assessment. Finally, and due to the large sample size, latent variable modelling techniques were used to assess inter-rater reliability. ${ }^{25}$ The significance level was set to $\mathrm{p}<0.05$. Effect sizes are presented by Cohen's $\mathrm{d}$. When participants completed fewer than $95 \%$ of the cases we did not process their survey (approximately 1500 responses).
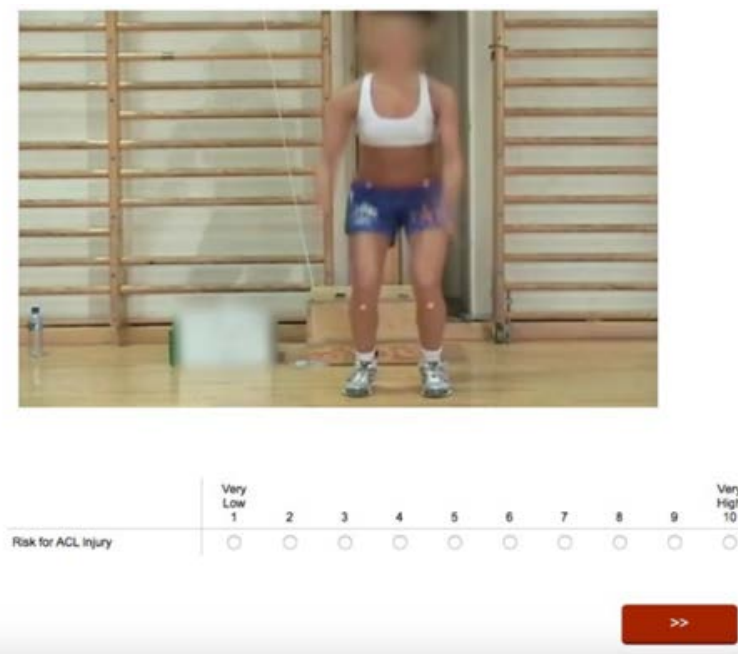

Figure 1 Screen shot of a risk rating assessment in the survey. 
Table 1 Demographic data

\begin{tabular}{|c|c|c|c|c|c|c|c|c|c|c|c|c|c|c|c|}
\hline \multirow[b]{2}{*}{ Occupation } & \multirow[b]{2}{*}{$n=237$} & \multicolumn{2}{|c|}{$\begin{array}{l}\text { Gender } \\
(n=236)\end{array}$} & \multirow{2}{*}{$\begin{array}{l}\begin{array}{l}\text { Age } \\
(n=237)\end{array} \\
\begin{array}{l}\text { Mean } \\
\text { (SD) }\end{array}\end{array}$} & \multicolumn{4}{|c|}{$\begin{array}{l}\text { Working with athletes }(\%) \\
(n=233)\end{array}$} & \multicolumn{5}{|c|}{$\begin{array}{l}\text { Years of experience in current occupation (\%) } \\
(n=236)\end{array}$} & \multicolumn{2}{|c|}{$\begin{array}{l}\text { Assessed VDJ } \\
\text { test before }(\%) \\
(n=237)\end{array}$} \\
\hline & & Male & Female & & Yes & $\begin{array}{l}\text { Within the } \\
\text { last } 5 \text { years }\end{array}$ & $\begin{array}{l}\text { Within the } \\
\text { last } 10 \text { years }\end{array}$ & No & $0-2$ & $3-5$ & $5-8$ & $8-12$ & $12+$ & Yes & No \\
\hline Physician* & 20 & 13 & 7 & $43.8(11.9)$ & 65 & 5 & 0 & 10 & 10 & 25 & 10 & 10 & 45 & 25 & 75 \\
\hline Certified athletic trainer & 15 & 11 & 4 & $40.2(8.3)$ & 87 & 13 & 0 & 0 & 0 & 20 & 0 & 27 & 47 & 53 & 47 \\
\hline Coach & 20 & 14 & 6 & $40.8(11.4)$ & 85 & 0 & 5 & 10 & 5 & 25 & 30 & 10 & 30 & 45 & 55 \\
\hline $\begin{array}{l}\text { Strength/conditioning } \\
\text { coach }\end{array}$ & 12 & 10 & 2 & $31.5(8.0)$ & 10 & 2 & 0 & 0 & 8 & 33 & 33 & 17 & 8 & 75 & 25 \\
\hline Physical therapist $†$ & 110 & 71 & 38 & $35.3(9.8)$ & 76 & 11 & 1 & 12 & 11 & 27 & 22 & 14 & 26 & 66 & 34 \\
\hline Researcher $\ddagger$ & 34 & 24 & 10 & $38.0(10.7)$ & 47 & 41 & 6 & 6 & 18 & 12 & 21 & 15 & 35 & 53 & 47 \\
\hline Student & 19 & 11 & 8 & $25.4(4.3)$ & 47 & 37 & 5 & 11 & 63 & 21 & 16 & 0 & 0 & 21 & 79 \\
\hline Other & 7 & 5 & 2 & $33.9(9.9)$ & 86 & 0 & 0 & 14 & 29 & 14 & 14 & 29 & 14 & 71 & 29 \\
\hline Total & 237 & 159 & 77 & 36.2 & 168 & 38 & 5 & 22 & 36 & 56 & 47 & 32 & 66 & 131 & 106 \\
\hline
\end{tabular}

*Working within general practice $(n=4)$, sports medicine $(n=12)$ and orthopaedics $(n=4)$.

tWorking in private clinic $(n=72)$, hospital inpatient/outpatient $(n=16)$, municipality physiotherapist $(n=5)$, rehabilitation clinic $(n=15)$.

$\ddagger$ Working with $A C L$-related research: $n=14$.

VDJ, vertical drop jump.

Where assessors reported being both a physical therapist and a researcher $(n=2)$, they were counted as being a physical therapist for our analysis.

\section{RESULTS}

\section{Assessor characteristics}

The survey was open from 22 March to 1 May. Over 1700 people opened the survey using the distributed link, but the majority did not complete it. Two hundred and thirty-seven assessors $(32.5 \%$ women and $67.5 \%$ men, mean age $36 \pm 11$ years) completed the online survey. About one half of the assessors were physiotherapists $(n=110,46 \%)$. Seventy-one per cent of the assessors reported that they currently were working with athletes, and $55 \%$ of the assessors reported that they have assessed performance of the VDJ test before (table 1).

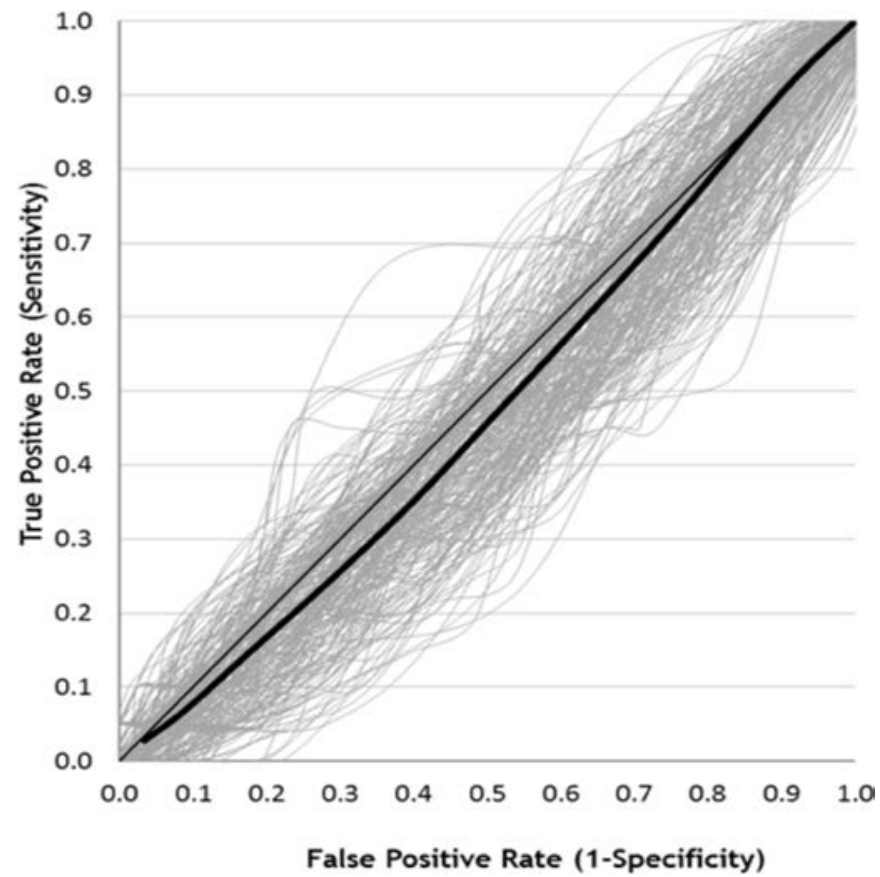

Figure 2 Individual (grey shaded lines) and average (thick black line) receiver operating characteristic curve for all 237 assessors. The thin black line represent the diagonal line.

\section{Risk classification accuracy}

Receiver operating curves are presented in figure 2. In 12 video clips, one score out of 237 was missing. Individual AUC values ranged from 0.36 to 0.60 . Average AUC for each group ranged from 0.45 to 0.47 (table 2). There were no significant differences between groups $(\mathrm{p}=0.67)$. The mean rating score of the injured players was $4.5 / 10( \pm 1.7 \mathrm{SD})$ whereas the mean score of the non-injured players was 4.8/10 ( $\pm 1.7 \mathrm{SD})(\mathrm{p}=0.52, \mathrm{~d}=0.16)$.

Sensitivity analysis of ROC curves calculated with adjusted ratio of injured and non-injured players showed no different results than the original ROC curve analysis (mean $0.43,95 \%$ CI 0.40 to 0.47 ). The subanalysis of the crowd sourced data did not give any different results (table 3 ). Latent variable modelling showed high inter-rater reliability $(r=0.75)$ between assessors when rating injury risk (figure 3 ). The assessors reported an overall confidence score of $6.0( \pm 1.9 S D)$ out of 10 for performing this injury risk assessment.

\section{Use of cues}

Inward/outward knee motion, knee position in landing and landing symmetry were the three cues the assessors most frequently reported that they used for injury risk assessment. These cues were used by $99.2 \%, 99.6 \%$ and $98.7 \%$ of the assessors, respectively. Assessors also rated the importance of these factors when assessing ACL injury risk giving inward/outward knee motion a score of 8.8 (95\% CI 8.7 to 9.0$)$, knee position in landing 9.0 (95\% CI 8.8 to 9.1) and landing symmetry 8.1 (95\% CI 7.9 to 8.3 ) on a scale ranging from 1 to 10 (see figure 4). Jump alignment and landing stiffness were also factors the assessors frequently reported that they used in the assessment, 96.6\% and $95.8 \%$ respectively.

\section{DISCUSSION}

This study revealed that observational assessment of the VDJ test cannot be used to assess ACL injury risk in this population of elite female handball and football players. The results from ROC curve analysis showed that AUC values ranged from 0.36 to 0.60 , meaning that the individual risk rating ability generally was no better than tossing a coin. No differences were identified between groups with different occupational backgrounds. Inward/outward knee motion, knee position in landing and landing symmetry were all cues used by nearly $100 \%$ of the 


\begin{tabular}{lrll}
$\begin{array}{l}\text { Table } 2 \\
95 \% \mathrm{Cl}\end{array}$ & Mean area under the curve values for each occupation with \\
\hline Occupation & $\mathbf{N}$ & Mean & $95 \% \mathrm{Cl}$ \\
\hline Physician & 20 & 0.47 & 0.44 to 0.49 \\
Certified athletic trainer & 15 & 0.45 & 0.43 to 0.47 \\
Coach & 20 & 0.46 & 0.44 to 0.48 \\
\hline Strength and conditioning coach & 12 & 0.45 & 0.43 to 0.48 \\
Physical therapist & 110 & 0.47 & 0.46 to 0.48 \\
\hline Researcher & 34 & 0.47 & 0.46 to 0.49 \\
Student & 19 & 0.47 & 0.45 to 0.49 \\
Other & 7 & 0.46 & 0.43 to 0.50 \\
Average & 237 & $\mathbf{0 . 4 7}$ & $\mathbf{0 . 4 6}$ to 0.47 \\
\hline
\end{tabular}

assessors and rated as cues with high importance (over 8/10) for assessing ACL injury risk.

Despite of the possibility to assess all thinkable movement characteristics, this study indicates that visual assessment of the VDJ performance is no better than three-dimensional motion analyses for identifying players at risk of ACL injury. However, although a vast number of motion and person characteristics were reported to be assessed (figure 3), it seems that the main focus of the assessors was similar to that of previous twodimensional video-based analyses. ${ }^{17-19} 26$ The assessors reported that they focused predominantly on frontal plane knee motion (knee placement in landing and inward/outward knee motion) in their assessment and considered it to be an important factor (9/10) for assessing ACL injury risk. High inter-rater reliability between assessors indicates that individuals were utilising similar cues, but that these cues do not provide useful information for assessing injury risk.

A critical question is therefore whether the VDJ test is challenging enough for these elite players to detect factors that potentially are associated with increased ACL injury risk. The test does not include changes in direction, which is commonly seen in the moment of injury. Moreover, the load is more or less equally distributed to both legs during landing in a VDJ test. In contrast, ACL injuries typically occur in side step cutting or one-legged landings. ${ }^{10} 1227$ Moreover, the test is preplanned, meaning that players do not have to react and make sudden decisions based on outer interference, in contrast to a game play situation.

Targeting movement patterns is an important part of effective preventative exercise programme that will reduce the risk of sustaining an ACL injury, ${ }^{28} 29$ and to date there is strong evidence indicating that we should keep encouraging athletes to engage in preventative exercise programme providing feedback on knee alignment, soft landings, even if prediction of future injury with sufficient level of accuracy seems unlikely. ${ }^{30}$ Although the VDJ test may provide information about movement patterns

\begin{tabular}{|c|c|c|c|c|c|c|c|c|}
\hline \multirow[b]{2}{*}{ Group } & \multirow[b]{2}{*}{ n } & \multicolumn{2}{|c|}{ Injured rating } & \multicolumn{2}{|c|}{$\begin{array}{l}\text { Non-injured } \\
\text { rating }\end{array}$} & \multirow{2}{*}{$\begin{array}{l}\text { Number } \\
\text { of injured } \\
\text { correctly } \\
\text { classified }\end{array}$} & \multirow[b]{2}{*}{$P$ value } & \multirow[b]{2}{*}{ Cohen's d } \\
\hline & & Mean & SD & Mean & SD & & & \\
\hline $\begin{array}{l}\text { Physical } \\
\text { therapists }\end{array}$ & 110 & 4.3 & 1.6 & 4.5 & 1.7 & 1 out of 20 & 0.58 & 0.15 \\
\hline $\begin{array}{l}\text { High ACL-IQ } \\
\text { (1SD above } \\
\text { mean)* }\end{array}$ & 29 & 4.7 & 2.1 & 5.0 & 2.1 & 2 out of 20 & 0.48 & 0.18 \\
\hline Entire sample & 237 & 4.5 & 1.7 & 4.8 & 1.7 & 1 out of 20 & 0.52 & 0.16 \\
\hline
\end{tabular}

See Petushek ${ }^{4}$ for psychometric characteristics of this tool.

*ACL Injury Risk Estimation Quiz (ACL-IQ) is a five-item video-based skill assessment to evaluate the ability of individuals to visually estimate risk for $\mathrm{ACL}$ injury using the drop vertical jump exercise.

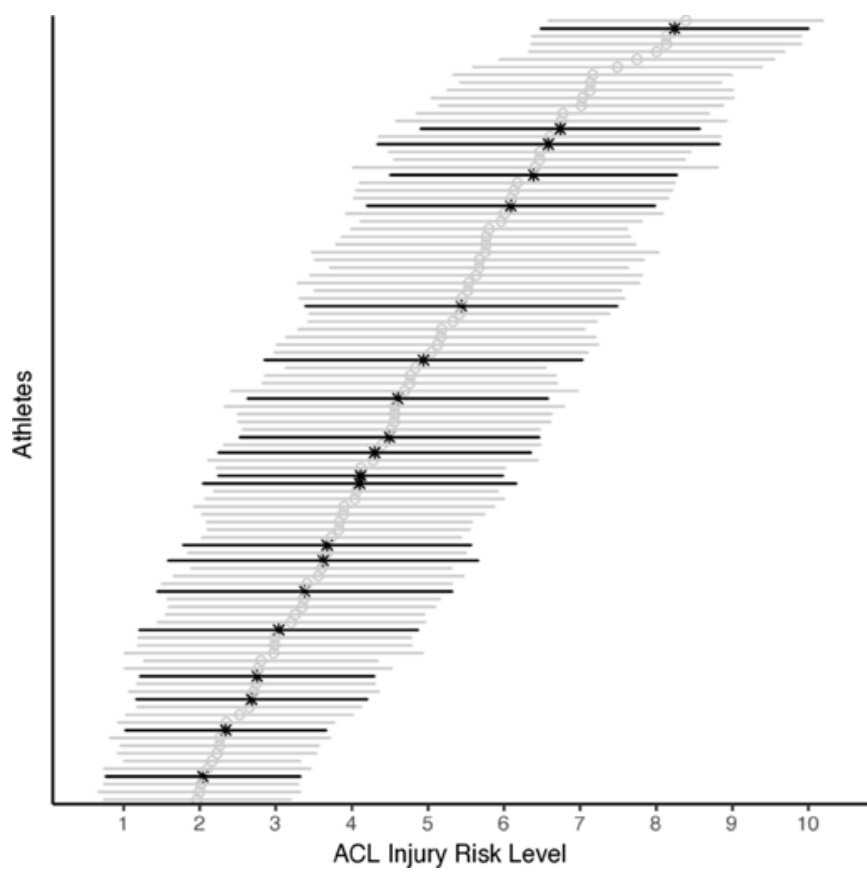

Figure 3 Mean individual athlete risk rating across all raters. Error bars indicate SD. Injured players are marked in bold black.

and modifiable risk factors in some groups of athletes, ${ }^{17} 19$ the current study reinforces that frontal plane assessment of the VDJ test does not provide useful information to predict ACL injury in this cohort of female elite football and handball players.

Interestingly, despite the low accuracy, the assessors generally reported moderate to high levels of confidence in their risk rating assignment (mean $6.0 \pm 1.9$ on a scale from 1 to 10 with 10 being high confidence). This indicates poor judgement calibration and adds data to support the unskilled and unaware phenomena, ${ }^{31}$ indicating that people tend to overestimate their abilities and lack the ability to evaluate how well they are performing. Based on our results it is important to acknowledge that individuals should not be confident when screening ACL injury risk through visual assessment of the VDJ test in this population.

The present study has limitations that should be taken into consideration when interpreting these results. First, the assessors

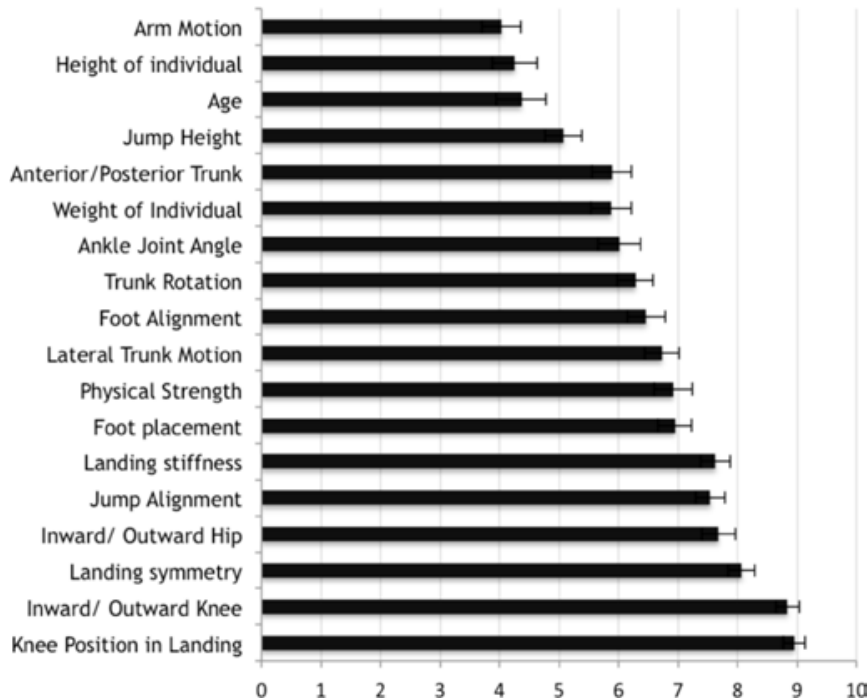

Figure 4 Importance of cues (with 95\% Cls). 
only assessed the player's movements from a frontal plane view. Less knee flexion ${ }^{10} 11161932-35$ during landing has been suggested to be associated with increased ACL injury risk, although not in all studies. ${ }^{18}$ This factor might have been easier to assess from a sagittal plane view. Nevertheless, landing stiffness can still be evaluated from a frontal plane view-based on landing depth.

Second, the picture quality and zoom factor differed slightly between the different test sessions. This may have prevented assessment of fine details in the movement patterns. However, it seems unlikely that assessment of the cues given in figure 4 would change significantly with higher image quality. Importantly, the assessors were given the opportunity to watch the clips as many times as they wanted, allowing an in-depth assessment.

Third, despite the limitations of three-dimensional motion analysis, visual inspection of joint kinematics in complex tasks has proven to be even less accurate. ${ }^{36}$ However, for the pure frontal plane assessment of a VDJ, the problem of for example, soft tissue artefacts is less of a problem in visual assessment. Moreover, a previous study ${ }^{3}$ reported good agreement between subjective assessments and three-dimensional motion-based measurements of frontal plane knee control.

Finally, it is possible that some of the players in the non-injury group would sustain an ACL injury after our observation period, thus misclassifying them. The players were followed prospectively until March 2014. However, as there is no difference in the risk assessment of injured and non-injured athletes, it seems highly unlikely that this would change our conclusion. It is still possible that the results of this study may have been different in a different population, for example, adolescent and male players.

\section{CONCLUSION}

The present study documents that sports medicine professionals and coaches cannot identify female elite handball and football players at increased risk of ACL injury by visually assessing their performance of the VDJ test. ROC curve analysis reveal a predictive ability no better than chance. Despite this fact, sports medicine professionals and coaches generally feel confident when assessing ACL injury risk in this population of elite female athletes.

\section{What are the findings?}

Sports medicine professionals and coaches show high levels of inter-rater consistency when assessing ACL injury risk.

- Sports medicine professionals and coaches have moderate to high level of confidence in $\mathrm{ACL}$ injury risk assessment.

- However, observational rating of the vertical drop jump (VDJ) test cannot predict $\mathrm{ACL}$ injury in female elite athletes.

\section{How might it impact on clinical practice in the future?}

- The VDJ test should not be used for identifying female elite football and handball players at risk of sustaining an ACL injury.

- Sports medicine professionals and coaches should be cautious interpreting results from their visual assessment of the VDJ test.

\section{Twitter Anne Inger Mørtvedt @AnnelMort}

Acknowledgements The Oslo Sports Trauma Research Center has been established at the Norwegian School of Sport Sciences through generous grants from the Royal Norwegian Ministry of Culture, the South-Eastern Norway Regional Health Authority, the International Olympic Committee, the Norwegian
Olympic Committee and Confederation of Sport, and Norsk Tipping AS. The authors are grateful to the assessors, and to all the players who participated in the study.

Contributors All the authors have contributed to the reporting of the work described in the article.

Funding The Oslo Sports Trauma Research Center has been established at the Norwegian School of Sport Sciences through generous grants from the Royal Norwegian Ministry of Culture, the South-Eastern Norway Regional Health Authority, the International Olympic Committee, the Norwegian Olympic Committee and Confederation of Sport, and Norsk Tipping AS.

Competing interests None declared.

Patient consent for publication Not required.

Ethics approval Approved by the Regional Commitees For Medical And Health Research Ethics - 2010/3153.

Provenance and peer review Not commissioned; externally peer reviewed.

Data availability statement All data relevant to the study are included in the article or uploaded as supplementary information.

Open access This is an open access article distributed in accordance with the Creative Commons Attribution Non Commercial (CC BY-NC 4.0) license, which permits others to distribute, remix, adapt, build upon this work non-commercially, and license their derivative works on different terms, provided the original work is properly cited, appropriate credit is given, any changes made indicated, and the use is non-commercial. See: http://creativecommons.org/licenses/by-nc/4.0/.

\section{ORCID iD}

Anne Inger Mørtvedt http://orcid.org/0000-0002-5179-9057

\section{REFERENCES}

1 Sugimoto D, Myer GD, Barber Foss KD, et al. Critical components of neuromuscular training to reduce $A C L$ injury risk in female athletes: meta-regression analysis. $\mathrm{Br}$ J Sports Med 2016:50:1259-66.

2 Petushek EJ, Sugimoto D, Stoolmiller M, et al. Evidence-Based best-practice guidelines for preventing anterior cruciate ligament injuries in young female athletes: a systematic review and meta-analysis. Am J Sports Med 2019;47:1744-53.

3 Nilstad A, Andersen TE, Kristianslund E, et al. Physiotherapists can identify female football players with high knee valgus angles during vertical drop jumps using realtime observational screening. J Orthop Sports Phys Ther 2014;44:358-65.

4 Petushek EJ, Cokely ET, Ward P, et al. Injury risk estimation expertise: assessing the ACL injury risk estimation quiz. Am J Sports Med 2015:43:1640-7.

5 Rabin A, Levi R, Abramowitz S, et al. A new real-time visual assessment method for faulty movement patterns during a jump-landing task. Phys Ther Sport 2016:20:7-12.

6 Stensrud S, Myklebust G, Kristianslund E, et al. Correlation between two-dimensional video analysis and subjective assessment in evaluating knee control among elite female team handball players. Br J Sports Med 2011;45:589-95.

7 Ekegren CL, Miller WC, Celebrini RG, et al. Reliability and validity of observational risk screening in evaluating dynamic knee valgus. J Orthop Sports Phys Ther 2009;39:665-74

8 Whatman C, Hing W, Hume P. Physiotherapist agreement when visually rating movement quality during lower extremity functional screening tests. Phys Ther Sport 2012:13:87-96.

9 Whatman C, Hume P, Hing W. The reliability and validity of physiotherapist visual rating of dynamic pelvis and knee alignment in young athletes. Phys Ther Sport 2013:14:168-74

10 Krosshaug T, Nakamae A, Boden BP, et al. Mechanisms of anterior cruciate ligament injury in basketball: video analysis of 39 cases. Am J Sports Med 2007;35:359-67.

11 Koga H, Nakamae A, Shima Y, et al. Mechanisms for noncontact anterior cruciate ligament injuries: knee joint kinematics in 10 injury situations from female team handball and basketball. Am J Sports Med 2010;38:2218-25.

12 Waldén $\mathrm{M}$, Krosshaug T, Bjørneboe J, et al. Three distinct mechanisms predominate in non-contact anterior cruciate ligament injuries in male professional football players: a systematic video analysis of 39 cases. Br J Sports Med 2015;49:1452-60.

13 Koga H, Nakamae A, Shima Y, et al. Hip and ankle kinematics in noncontact anterior cruciate ligament injury situations: video analysis using model-based image matching. Am J Sports Med 2018;46:333-40.

14 Redler LH, Watling JP, Dennis ER, et al. Reliability of a field-based drop vertical jump screening test for ACL injury risk assessment. Phys Sportsmed 2016;44:46-52.

15 McLean SG, Walker K, Ford KR, et al. Evaluation of a two dimensional analysis method as a screening and evaluation tool for anterior cruciate ligament injury. Br J Sports Med 2005;39:355-62.

16 Ford KR, Myer GD, Hewett TE. Valgus knee motion during landing in high school female and male basketball players. Med Sci Sports Exerc 2003;35:1745-50.

17 Hewett TE, Myer GD, Ford KR, et al. Biomechanical measures of neuromuscular control and valgus loading of the knee predict anterior cruciate ligament injury risk in female athletes: a prospective study. Am J Sports Med 2005;33:492-501. 


\section{Original research}

18 Krosshaug T, Steffen K, Kristianslund E, et al. The vertical drop jump is a poor screening test for $\mathrm{ACL}$ injuries in female elite soccer and Handball players: a prospective cohort study of 710 athletes. Am J Sports Med 2016;44:874-83.

19 Leppänen M, Pasanen K, Kujala UM, et al. Stiff Landings are associated with increased ACL injury risk in young female Basketball and Floorball players. Am J Sports Med 2017;45:386-93.

20 Fleuret F, Li T, Dubout C, et al. Comparing machines and humans on a visual categorization test. Proc Natl Acad Sci U S A 2011;108:17621-5.

21 Steffen K, Nilstad A, Kristianslund EK, et al. Association between lower extremity muscle strength and noncontact ACL injuries. Med Sci Sports Exerc 2016;48:2082-9.

22 Steffen K, Nilstad A, Krosshaug T, et al. No association between static and dynamic postural control and $\mathrm{ACL}$ injury risk among female elite handball and football players: a prospective study of 838 players. Br J Sports Med 2017;51:253-9.

23 Myklebust G, Bahr R, Nilstad A, et al. Knee function among elite handball and football players 1-6 years after anterior cruciate ligament injury. Scand J Med Sci Sports 2017;27:545-53.

24 Hosmer DWL. Stanley Sturdivant RX. In: Applied logistic regression. 3rd edn. John Wiley \& Sons, Incorporated, 2013.

25 Raykov T, Dimitrov DM, von Eye A, et al. Interrater Agreement Evaluation:A Latent Variable Modeling Approach. Educ Psychol Meas 2013;73:512-31.

26 Smith HC, Johnson RJ, Shultz SJ, et al. A prospective evaluation of the landing error scoring system (less) as a screening tool for anterior cruciate ligament injury risk. Am J Sports Med 2012;40:521-6.

27 Olsen O-E, Myklebust G, Engebretsen L, et al. Injury mechanisms for anterior cruciate ligament injuries in team handball: a systematic video analysis. Am J Sports Med 2004:32:1002-12.
28 Taylor JB, Waxman JP, Richter SJ, et al. Evaluation of the effectiveness of anterior cruciate ligament injury prevention programme training components: a systematic review and meta-analysis. Br J Sports Med 2015;49:79-87.

29 Sugimoto D, Myer GD, McKeon JM, et al. Evaluation of the effectiveness of neuromuscular training to reduce anterior cruciate ligament injury in female athletes: a critical review of relative risk reduction and numbers-needed-to-treat analyses. $\mathrm{Br} J$ Sports Med 2012;46:979-88.

30 Bahr R. Why screening tests to predict injury do not work-and probably never will...: a critical review. Br J Sports Med 2016;50:776-80.

31 Kruger J, Dunning D. Unskilled and unaware of it: how difficulties in recognizing one's own incompetence lead to inflated self-assessments. J Pers Soc Psychol 1999;77:1121-34

32 Cochrane JL, Lloyd DG, Buttfield A, et al. Characteristics of anterior cruciate ligament injuries in Australian football. J Sci Med Sport 2007;10:96-104.

33 Yu B, Garrett WE. Mechanisms of non-contact ACL injuries. Br J Sports Med 2007:41 Suppl 1:i47-51.

34 Renstrom $\mathrm{P}$, Ljungqvist $\mathrm{A}$, Arendt $\mathrm{E}$, et al. Non-Contact ACL injuries in female athletes: an international Olympic Committee current concepts statement. Br J Sports Med 2008:42:394-412.

35 Fagenbaum R, Darling WG. Jump landing strategies in male and female college athletes and the implications of such strategies for anterior cruciate ligament injury. Am J Sports Med 2003;31:233-40.

36 Krosshaug T, Nakamae A, Boden B, et al. Estimating 3D joint kinematics from video sequences of running and cutting maneuvers--assessing the accuracy of simple visual inspection. Gait Posture 2007;26:378-85. 